\title{
Clinical experience with clarithromycin for the treatment of respiratory tract infections
}

RONALD F GROSSMAN, MD, FRCPC, FACP

E RYTHROMYCIN, THE FIRST ANTIBIOTIC OF THE MACROLIDE class, was discovered in 1952 from the metabolic products of a strain of Streptomyces erythreus (1). Despite widespread use of this drug, specific problems have limited its usefulness. Poor oral bioavailability secondary to inactivation in an acidic medium necessitates the use of enteric coating or changes in formulation (2). A metabolite has been identified which binds to motilin-like receptors in the gastrointestinal smooth muscle (3). Activation of this receptor leads to an increase in interdigestive gastric motility and side effects. Finally, with a short half-life requiring four daily doses and a perceived lack of efficacy against Haemophilus influenzae, erythromycin has been used as a second line drug in the treatment of respiratory tract infections.

Clarithromycin has been introduced recently for use in Canada. This novel macrolide has many properties which would render it effective in a variety of infections. This article will review those properties briefly and the clinical efficacy of clarithromycin for the treatment of respiratory tract infections.

\section{IN VITRO ACTIVITY}

Clarithromycin demonstrates excellent activity against many Gram-positive organisms, anaerobic organisms, Chlamydia species, Mycoplasma species,
Moraxella catarrhalis and Legionella species (4). In general it is about $1 \log$ dilution more potent than erythromycin against most respiratory pathogens. The major metabolite of clarithromycin, a 14-hydroxy derivative, is active especially against $H$ influenzae (5). There are in vitro and in vivo data to suggest that the parent compound and the metabolite are active in an additive fashion, thus rendering Haemophilus species susceptible to this antimicrobial (6).

\section{PHARMACOKINETIC FEATURES}

Clarithromycin is well absorbed from the gastrointestinal tract, is approximately $55 \%$ bioavailable and is stable in an acid environment (7). It diffuses well into respiratory tract fluids and tissues. Tonsillar, sinus, bronchial mucosal, alveolar macrophage and lung tissue levels far exceed serum levels both for the parent compound and the 14-hydroxy derivative $(8,9)$. A long half-life of $3.5 \mathrm{~h}$ for the $250 \mathrm{mg}$ dose and $4.9 \mathrm{~h}$ for the $500 \mathrm{mg}$ dose allows twice daily dosing.

\section{ADVERSE EFFECTS}

About 3\% of patients receiving the drug have withdrawn from clinical trials because of adverse effects (10). The incidence of these effects has been the same as comparator agents, particularly beta-lactam antibiotics, and significantly less than erythromycin. The 
most commonly reported side effects are nausea (4\%), diarrhea $(3 \%)$, dyspepsia $(2 \%)$, abdominal pain $(2 \%)$ and headache $(2 \%)$.

Given the microbiological spectrum covered, excellent pharmacokinetics and favourable side effect profile, clarithromycin should be an effective agent in the treatment of respiratory tract infections. The rest of this review will cover the clinical experience with this agent in the treatment of upper and lower respiratory tract infections.

\section{UPPER RESPIRATORY TRACT INFECTIONS}

Pharyngitis and tonsillitis: Group A streptococcus is still the chief etiological agent responsible for pharyngitis. This organism remains highly susceptible to penicillin and other beta-lactam antibiotics. Erythromycin has been shown to be effective as an alternative agent.

The efficacy of clarithromycin has been examined in two large, multicentre, double-blind, randomized trials $(11,12)$. In the first study patients were randomized to receive clarithromycin $250 \mathrm{mg}$ every $12 \mathrm{~h}$ or penicillin VK $250 \mathrm{mg}$ every $6 \mathrm{~h}$ (11). In total, 243 patients were enrolled in the study, with 128 patients receiving clarithromycin and 115 patients receiving penicillin VK. In the patients in whom a baseline pathogen could be isolated the clinical success rate with clarithromycin was $100 \%$ (clinical cure rate $96 \%$ and clinical improvement $4 \%$ ), a result which was identical to the group that received pencillin VK. The bacteriological response rate was $98 \%$ for both the clarithromycin-treated patients and the penicillin VK-treated patients. The side effect profile of the two drugs was similar. In a second study 65 patients received clarithromycin while 63 patients received pencillin VK (12). The post treatment clinical success and bacteriological cure rates for clarithromycin were 95 and $88 \%$, respectively, with both rates $91 \%$ for penicillin VK. The conclusions of these studies were that clarithromycin was as safe and effective as penicillin VK in the treatment of streptococcal pharyngitis.

The outcome of these two studies and three other studies were summarized recently (13). In five multicentre trials, 1031 patients with documented streptococcal pharyngitis were randomized to receive a 10 day course of clarithromycin $250 \mathrm{mg}$ ql2h ( $\mathrm{n}=468)$, a comparator agent, penicillin VK, $250 \mathrm{mg}$ q8h (one study, $\mathrm{n}=227$ ) or $250 \mathrm{mg}$ q6h (two studies, $\mathrm{n}=178$ ), or erythromycin stearate $500 \mathrm{mg}$ q12h (two studies, $\mathrm{n}=158$ ). The clinical success rate and bacteriological eradication rate for clarithromycin was 98 and 95\%, respectively. There were no differences compared with the reference agents.

From these studies it appears clear that clarithromycin is effective in the treatment of streptococcal pharyngitis.

Sinusitis: Sinusitis has been shown to be caused by Streptococcus pneumoniae, H influenzae, primarily nontypeable strains, and $M$ catarrhalis. A significant minor- ity of Haemophilus strains produce beta-lactamase as do the majority of Moraxella strains $(14,15)$. Given the excellent tissue penetration of clarithromycin and the activity against beta-lactamase producing organisms, it seems likely that clarithromycin would be effective in this indication.

Clarithromycin has been compared with amoxicillin in two studies $(16,17)$ and amoxicillin-clavulanate in another (18). In a multicentre, single-blinded study conducted in Finland, 50 patients with clinical and radiological evidence of acute maxillary sinusitis received clarithromycin $500 \mathrm{mg}$ ql2h or amoxicillin $500 \mathrm{mg}$ q8h (16). Both antibiotics achieved a clinical success rate of $91 \%$ within $48 \mathrm{~h}$ post treatment. Radiological resolution was seen in $91 \%$ of clarithromycin-treated patients and $89 \%$ of patients receiving amoxicillin. Bacteriological cure was achieved in 88 and $91 \%$ of evaluable patients for clarithromycin and amoxicillin, respectively. The response rate for amoxicillin may be higher in this study than in clinical practice since beta-lactamase producing strains were excluded from the study.

In a multicentre, single-blinded study conducted in Canada, 70 patients received clarithromycin $500 \mathrm{mg}$ ql2h while 72 patients received amoxicillin $500 \mathrm{mg} \mathrm{q} 8 \mathrm{~h}$ (17). At $48 \mathrm{~h}$ post therapy, clinical success was achieved in $85 \%$ of clarithromycin-treated patients and $80 \%$ of amoxicillin-treated patients. The radiological resolution rates were similar.

In another multicentre, single-blinded trial conducted in Canada, 87 patients received clarithromycin $500 \mathrm{mg}$ ql2h while 84 patients received amoxicillin-clavulanate $500 \mathrm{mg}$ q8h (18). The clinical success rate and bacteriological eradication rate for clarithromycin were 89 and $91 \%$, respectively, while they were 100 and $96 \%$ for amoxicillin-clavulanate. Clarithromycin was better tolerated than amoxicillin-clavulanate in this study, with the clarithromycin-treated patients experiencing half the gastrointestinal side effects compared with the patients receiving amoxicillin-clavulanate.

From these studies it appears that clarithromycin is as effective as beta-lactams in the treatment of acute maxillary sinusitis.

\section{LOWER RESPIRATORY TRACT INFECTIONS} Acute exacerbations of chronic bronchitis: The major pathogens implicated in this clinical entity are the same as those identified in acute sinusitis. Recently, the value of antimicrobial agents for this disorder has been established $(19,20)$.

In a double-blind, randomized, multicentre trial, 111 patients with acute exacerbations of chronic bronchitis received clarithromycin $250 \mathrm{mg}$ q12h while 114 patients received ampicillin $250 \mathrm{mg}$ q6h (21). Both clarithromycin and ampicillin were effective with clinical success rates of 97 and $91 \%$, respectively. Pathogen eradication rates were $86 \%$ for clarithromycin and $88 \%$ 
for ampicillin, but patients who had beta-lactamase producing strains were excluded from the study. Although the incidence of gastrointestinal side effects was the same for both agents, there were a few more dropouts in the clarithromycin-treated group.

In a second, very similar trial involving 125 patients, clarithromycin-treated patients had a $96 \%$ clinical cure rate compared with a $91 \%$ rate for ampicillin-treated patients (22). The bacteriological cure rate was $96 \%$ for clarithromycin and $100 \%$ for ampicillin. In this study there were more gastrointestinal side effects with clarithromycin, but the dropouts were the same.

In two randomized, multicentre studies (one doubleblind and one single-blind), 96 patients received clarithromycin $500 \mathrm{mg}$ q12h while 92 received ampicillin $500 \mathrm{mg}$ q6h (23). The clinical success rate and bacteriological response rate for clarithromycin were 97 and 95\%, respectively, compared with 97 and 91\%, respectively, for ampicillin. The side effect profiles for the two drugs were similar.

Two studies have compared clarithromycin to cefuroxime and cefaclor for the same indication $(24,25)$. In these studies the $500 \mathrm{mg}$ dose of clarithromycin was compared with a $500 \mathrm{mg}$ dose of the comparator agent. The clinical response rate was the same for clarithromycin and cefuroxime but better for clarithromycin than cefaclor. The bacteriological response rates were the same. Clarithromycin and cefuroxime axetil had a similar incidence of gastrointestinal side effects, while cefaclor had fewer than clarithromycin in this study.

Several studies have examined patients suffering from a variety of lower respiratory tract infections including acute bronchitis, acute exacerbations of chronic bronchitis and pneumonia (26-29). Clarithromycin has been compared with amoxicillin, cefaclor and cefixime in double-blind, randomized trials. In all instances the clinical success rates and bacteriological eradication rates were similar.

Pneumonia: Pneumonia in the outpatient setting is most often caused by $S$ pneumoniae but other atypical organisms, such as Mycoplasma pneumoniae, Chlamydia pneumoniae and Legionella pneumophila have assumed increasing importance. The clinical presentation of patients infected with atypical organisms is often similar to those infected with the usual bacterial patho-

\section{REFERENCES}

1. Griffith RS. Pharmacology of erythromycin in adults. Pediatr Infect Dis 1986;5:130-40.

2. Kirst HA, Sides GD. New directions for macrolide antibiotics: Structural modifications and in vitro activity. Antimicrob Agents Chemother 1989;33:1413-8.

3. Omura S, Tsuzuki K, Sunazuka T, et al. Macrolides with gastrointestinal motor stimulating activity. J Med Chem 1987;30:1941-3.

4. Neu HC. The development of macrolides: Clarithromycin in perspective. J Antimicrob Chemother 1991;27

(Suppl A): 1-9.

5. Olsson-Liljequist B, Hoffman BM. In vitro activity gens and it is difficult to separate these entities on clinical grounds alone (30). Beta-lactam antibiotics are not considered the drugs of choice for treatment of atypical pathogens.

Several studies have examined the efficacy of clarithromycin in patients with community-acquired pneumonia $(31,32)$. Anderson and co-workers (31) compared clarithromycin $250 \mathrm{mg}$ q12h with erythromycin stearate $500 \mathrm{mg}$ q6h in a multicentre, double-blind, randomized trial. Clinical success and radiological response were similar in the two groups, but the side effects were less with clarithromycin. Chan and co-workers (32) compared clarithromycin $250 \mathrm{mg}$ ql2h to erythromycin stearate $500 \mathrm{mg}$ q6h in a multinational, multicentre randomized clinical trial. The clinical response rate and radiological resolution rate for clarithromycin-treated patients was 97 and 90\%, respectively, while it was 96 and $85 \%$ for the erythromycin-treated group. The patients receiving clarithromycin experienced fewer side effects than the erythromycin-treated patients.

Clarithromycin has been shown to be effective in the treatment of patients with pneumonia caused by $\mathrm{Myco}$ plasma (33), Chlamydia (34) and Legionella (35) species.

\section{SUMMARY}

Clarithromycin has demonstrated excellent clinical results in the treatment of upper and lower respiratory tract infections. In well designed, well conducted randomized clinical trials, clarithromycin has been shown to be as effective as the usual agents in the management of patients with streptococcal pharyngitis, sinusitis, acute exacerbations of chronic bronchitis, acute lower respiratory tract infections and pneumonia. In many instances the studies masked the potential advantage of clarithromycin compared with standard beta-lactam antibiotics, since beta-lactamase producing strains were excluded from most studies for ethical reasons. The side effect profile appears similar to most beta-lactam antibiotics and better than erythromycin. Given clarithromycin's spectrum of activity, excellent pharmacokinetics, few significant adverse effects and proven efficacy in the management of respiratory infections, it should prove useful in the physician's armamentarium.

of clarithromycin combined with its 14-hydroxy metabolite A-62671 against Haemophilus influenzae. J Antimicrob Chemother 1991;27 (Suppl A): 11-7.

6. Dabernat H, Delmas C, Seguy M, et al. The activity of clarithromycin and its 14-hydroxy metabolite against Haemophilus influenzae, determined by in vitro and serum bactericidal tests. J Antimicrob Chemother 1991;27(Suppl A): 19-30.

7. Chu SY, Wilson DS, Eason C, et al. Single- and multi-dose pharmacokinetics of clarithromycin. 30th Interscience Conference on Antimicrobial Agents for Chemotherapy. Atlanta, 1990. 
8. Fraschini F, Scaglione F, Pintucci G, et al. The diffusion of clarithromycin and roxithromycin into nasal mucosa, tonsil and lung in humans. J Antimicrob Chemother 1991;27(Suppl A):61-5.

9. Honeybourne D, Baldwin D, Greaves I, et al. Clarithromycin levels in human bronchial mucosa, alveolar macrophages, and serum. 1st International Conference on the Macrolides, Azalides and Streptogramins. Santa Fe, 1992:199.

10. Pichotta P, Gupta S, Prokocimer P, Pernet A. The overall safety of oral clarithromycin in comparative clinical studies. 30th Interscience Conference on Antimicrobial Agents for Chemotherapy. Atlanta, 1990: 1332.

11. Levenstein JH. Clarithromycin versus penicillin in the treatment of streptococcal pharyngitis. J Antimicrob Chemother 1991;27(Suppl A):67-74.

12. Bachand RT Jr. A comparative study of clarithromycin and penicillin VK in the treatment of outpatients with streptococcal pharyngitis. J Antimicrob Chemother 1991;27(Suppl A):75-82.

13. Prokocimer P. Treatment of streptococcal pharyngitis: A comparison of clarithromycin and other comparator agents. 7th Mediterranean Congress of Chemotherapy. Barcelona, 1990.

14. Doern GV, Jorgensen JH, Thornsberry C, et al. Prevalence of antimicrobial resistance among clinical isolates of Haemophilus influenzae. Antimicrob Agents Chemother 1988;32:180-5.

15. Hager H, Verghese A, Alvarez S, Berk SL. Branhamella catarrhalis respiratory infections. Rev Infect Dis 1987;9:1140-9.

16. Karma P, Pukander J, Penttilä M, et al. The comparative efficacy and safety of clarithromycin and amoxicillin in the treatment of outpatients with acute maxillary sinusitis. J Antimicrob Chemother 1991;27(Suppl A) $: 83-90$.

17. Dubois J, Saint Pierre C. Safety and efficacy of clarithromycin and amoxicillin in the treatment of patients with acute maxillary sinusitis. 1st International Conference on the Macrolides, Azalides and Streptogramins. Santa Fe, 1992: 228

18. Saint Pierre C, Dubois J, Prokocimer P, Drnec J. An evaluation of clarithromycin and amoxicillin/ clavulanate for the treatment of acute maxillary sinusitis. 1st International Conference on the Macrolides, Azalides and Streptogramins. Santa Fe, 1992: 229.

19. Anthonisen NR, Manfeda J, Warren CPW, et al. Antibiotic therapy in exacerbations of chronic obstructive pulmonary disease. Ann Intern Med 1987;106:196-204.

20. Murphy TF, Sethi S. Bacterial infection in chronic obstructive pulmonary disease. State of the art. Am Rev Respir Dis 1992;146:1067-83.

21. Bachand RT Jr. Comparative study of clarithromycin with ampicillin in the treatment of patients with acute bacterial exacerbations of chronic bronchitis. J Antimicrob Chemother 1991;27(Suppl A):91-100.

22. Aldons PM. A comparison of clarithromycin with ampicillin in the treatment of outpatients with acute bacterial exacerbations of chronic bronchitis.
J Antimicrob Chemother 1991;27:(Suppl A):101-8.

23. Vogel F, Aynilian G. Efficacy and safety of clarithromycin compared to ampicillin in the treatment of acute bacterial exacerbations of chronic bronchitis. 30th Interscience Conference on Antimicrobial Agents for Chemotherapy. Atlanta, 1990.

24. Jenkinson S, Anzuetto A, Smith B, Thakkar T. Clarithromycin compared to cefuroxime axetil in the treatment of acute exacerbation of chronic bronchitis. 1st International Conference on the Macrolides, Azalides and Streptogramins. Santa Fe, 1992: 235.

25. Spiritus E, Devcich K, Drnec J, Hallwas R. Clarithromycin vs cefaclor for acute exacerbations of bronchitis. 1st International Conference on the Macrolides, Azalides and Streptogramins. Santa Fe, 1992:239.

26. Mehtar S, Macklin JL, Coles SJ, et al. A double-blind, randomized study comparing clarithromycin, amoxicillin and cefaclor in the treatment of bronchitis. 1st International Conference on Macrolides, Azalides and Streptogramins. Santa Fe, 1992: 236.

27. Wettengel R. Comparison of clarithromycin and cefaclor in the treatment of mild-to-moderate bronchitis. 1st International Conference on Macrolides, Azalides and Streptogramins. Santa Fe, 1992: 240.

28. Prokocimer P. An evaluation of clarithromycin and cefixime for lower respiratory tract infections. 1st International Conference on Macrolides, Azalides and Streptogramins. Santa Fe, 1992: 243.

29. Climax J, Rice K, Northcutt V. Efficacy and safety of clarithromycin in the treatment of lower respiratory tract infections. 7th Mediterranean Congress of Chemotherapy. Barcelona, 1990.

30. Fang GD, Fine M, Orloff J, et al. New and emerging etiologies for community-acquired pneumonia with implications for therapy. Medicine 1990;69:307-16.

31. Anderson G, Esmonde TS, Coles S, et al. A comparative safety and efficacy study of clarithromycin and erythromycin stearate in community-acquired pneumonia. J Antimicrob Chemother 1991;27 (Suppl A):117-24.

32. Chan CK, Chien SM, Pichotta P, et al. Treatment of community-acquired pneumonia: a randomized, controlled trial comparing clarithromycin and erythromycin. 8th Mediterranean Congress of Chemotherapy. Athens, 1992.

33. Cassell GH, Drnec J, Pate M, et al. Mycoplasma pneumoniae: comparative efficacy of clarithromycin and erythromycin. 30th Interscience Conference on Antimicrobial Agents for Chemotherapy. Atlanta, 1990: 1333.

34. Marin R, Rank R, Perrson K, et al. Chlamydia pneumoniae (TWAR): Comparative efficacy of clarithromycin and erythromycin. 30th Interscience Conference on Antimicrobial Agents for Chemotherapy. Atlanta, 1990: 1334.

35. Hamedani P, Ali J, Hafeez S, et al. The safety and efficacy of clarithromycin in patients with legionella pneumonia. Chest 1991;100:1503-6. 


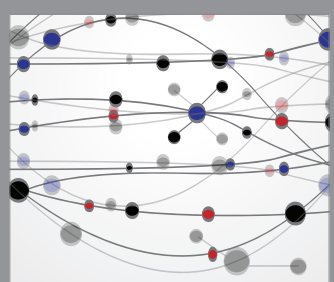

The Scientific World Journal
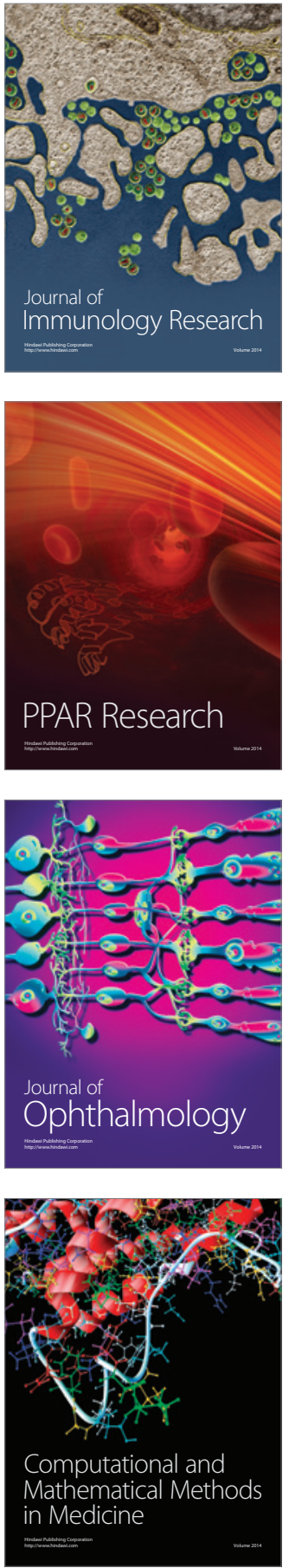

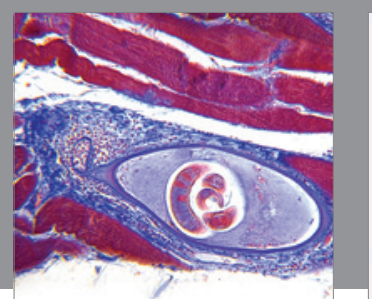

Gastroenterology Research and Practice

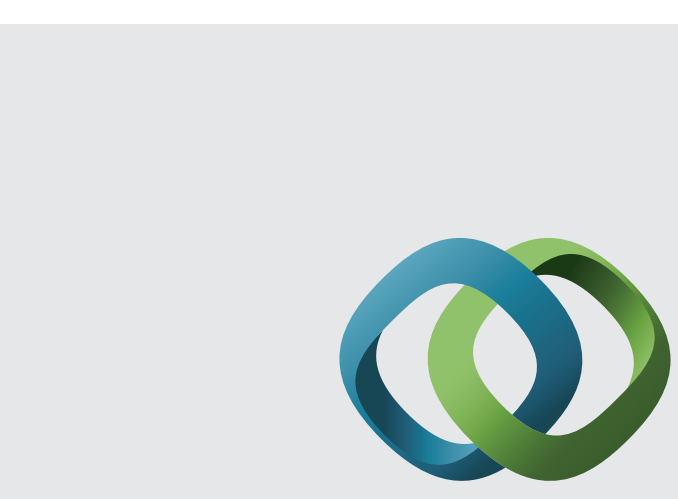

\section{Hindawi}

Submit your manuscripts at

http://www.hindawi.com
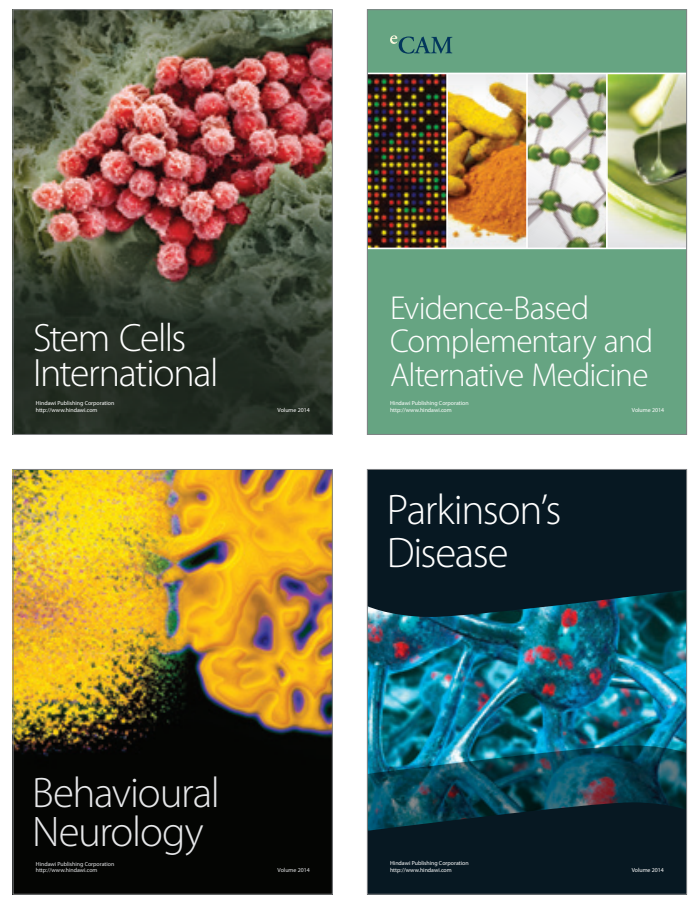
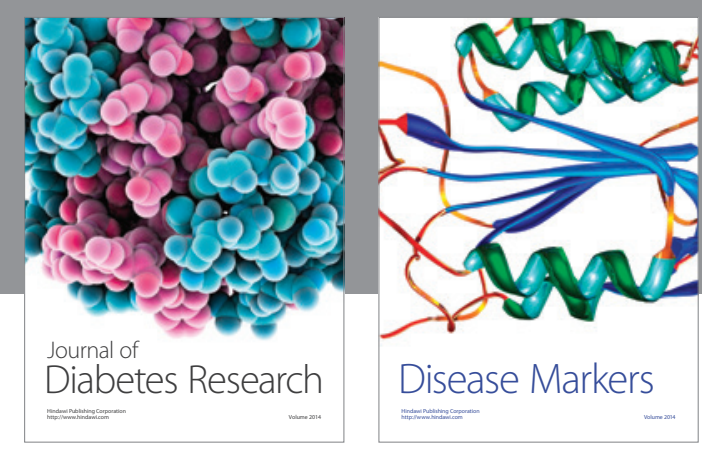

Disease Markers
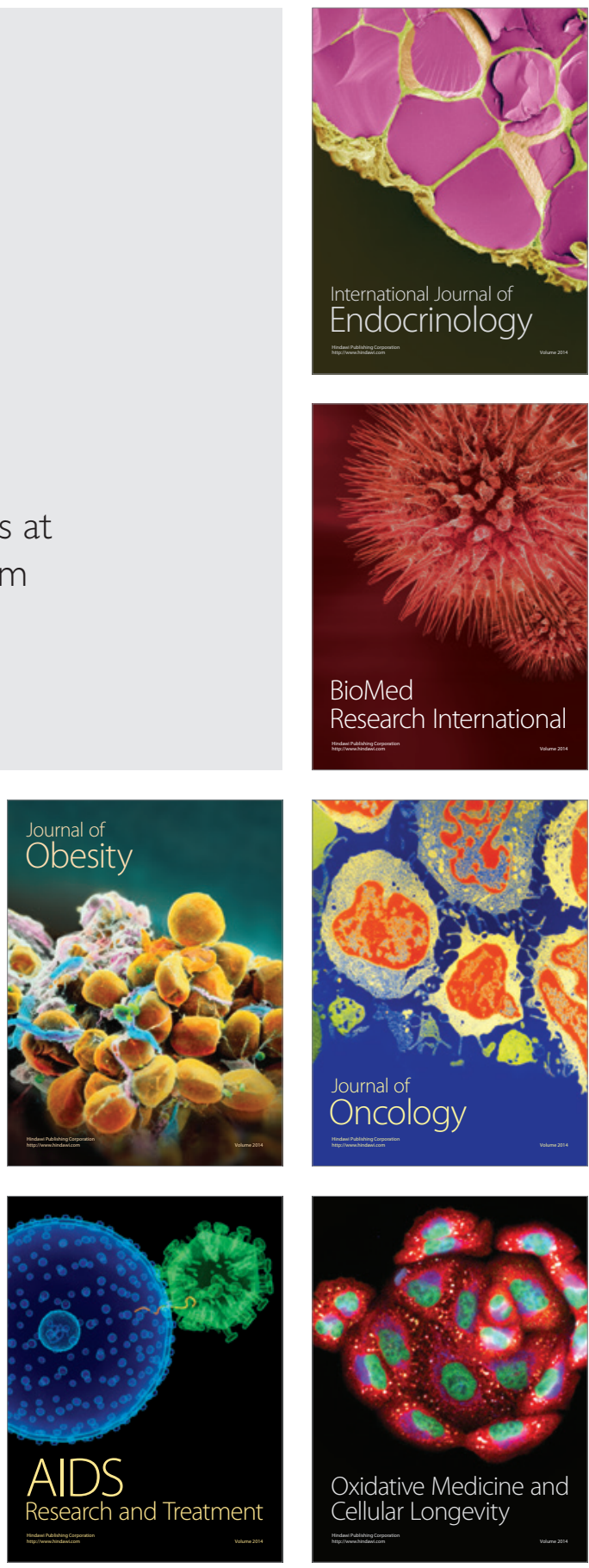